\title{
Supported Rehabilitation for Individuals Who Have Experienced a Stroke: A Pilot Control Trial
}

\author{
Charlotte Gaynor ${ }^{1}$, Laura Devaux ${ }^{1}$, Morley Stephanie'1, Kate Petropoulou' ${ }^{1}$, \\ Brendon Stubbs ${ }^{2}$, Andrew Soundy ${ }^{*}$ \\ ${ }^{1}$ Department of Physiotherapy, School of Sport, Exercise and Rehabilitation Sciences, \\ University of Birmingham, Edgbaston, Birmingham, England \\ ${ }^{2}$ Department of Health Service and Population Research, Kings College, London, England \\ Email: *A.A.Soundy@bham.ac.uk
}

Received 8 March 2016; accepted 10 May 2016; published 13 May 2016

Copyright (C) 2016 by authors and Scientific Research Publishing Inc.

This work is licensed under the Creative Commons Attribution International License (CC BY). http://creativecommons.org/licenses/by/4.0/

(c) (i) Open Access

\section{Abstract}

The purpose of this study was to pilot an innovative and supported intervention for individuals with a stroke. A pilot control trial with qualitative interviews was undertaken within a universitycommunity setting. Thirteen individuals who had experienced a stroke for periods of least 6 months (6 male, average 71 years) were assigned to the intervention group and 7 individuals ( 2 male, average age 67.9 years) assigned to the control group. Eight individuals from the intervention group completed a single interview. The procedures that related to recruitment and retention and data collection methods were considered. Outcome measures including; self-efficacy, falls self-efficacy and group membership, for both groups were taken at baseline, 11 weeks, 22 weeks. There was an additional assessment at 52 weeks for the intervention group. The structured interview was designed to focus on experiences of the intervention. Self-efficacy remained stable across time for both groups. An improvement in falls self-efficacy was noted in the intervention group at 11 weeks. Consistent improvement (from baseline) was observed in the identity scale across the 52 weeks. Qualitative data provided additional findings related to identity and confidence. Details considering recruitment and retention are also provided. This pilot study provided data that can be used for a further full-scale trial to be considered.

\section{Keywords}

Stroke, Pilot, Controlled Trial, Exercise, Rehabilitation

\footnotetext{
${ }^{*}$ Corresponding author.
}

How to cite this paper: Gaynor, C., Devaux, L., Stephanie, M., Petropoulou, K., Stubbs, B. and Soundy, A. (2016) Supported Rehabilitation for Individuals Who Have Experienced a Stroke: A Pilot Control Trial. Open Journal of Therapy and Rehabilitation, 4, 87-98. http://dx.doi.org/10.4236/ojtr.2016.42008 


\section{Introduction}

Stroke rehabilitation is defined as a multi-dimensional process that aims to restore or adapt a loss of physical or psychological function, with the long-term goal of improving participation in society [1]. Rehabilitation helps improve and manage long-term effects of stroke [2]. Physiotherapy plays an important role within this rehabilitation process, acting as a core part of the multi-disciplinary team [1]. Recent review evidence has suggested that physiotherapy interventions are effective for individuals who have suffered a stroke [3]. However, rehabilitation in UK is limited and is required for patients over longer periods of time [4]. For instance, 50\% of patients have indicated they have not received adequate rehabilitation support between 1 - 5 years post stroke, in addition to this, physiotherapists have reported that only $22 \%$ of individuals meet the goals set within care [2].

Post stroke, the effects of services such as physiotherapy have on the psychosocial outcomes (this includes psychological and social constructs challenged by stroke that impact on an individual's mental well-being) ${ }^{1}$, in contrast to physical outcomes, is less understood [5] [6]. For the purpose of this paper, we will focus on three important psychosocial constructs which are influenced by rehabilitation interventions, these include self-efficacy [7] [8], falls self-efficacy [9] and social identity [10] [11].

Discharge from inpatient services may be one time when patients are particularly vulnerable to psychological challenges. Reasons for this include feeling challenged by the impact of the stroke on their social identity-being isolated from others and lacking autonomous confidence in undertaking meaningful activities [12]. Initiating, re-establishing or maintaining a positive social identity, having access to meaningful relationships and feeling able to undertake activities is central to informing a patients hope and mental well-being [13]. However, lack of stroke specific rehabilitation can be limited outside hospital units [14], and further to this, where rehabilitation is accessed, rehabilitation professionals may (because of restrictions in the environment, policy of the hospital, or waiting lists) focus on functional goals and not have the time to consider the continuity in a patient's social identity, despite patients valuing this most when considering their goals [15].

Further to this, self-efficacy and self-management have been identified as important concepts directly associated with re-accessing meaningful and essential activities of daily living [16]. Supported stroke rehabilitation, for the purpose of this article, is considered rehabilitation that is supported by health care professionals, peers or others, which is able to promote continuity in social identity and self-management through being able to provide enhanced levels of social support through the use of volunteers. Social support in this sense is defined as informational provision, encouragement or bolstering ones' confidence, emotional support and listening, or tangible acts that assist access to rehabilitation services. But can also include a sense of belonging and unity in a group if rehabilitation is conducted in such a setting; see [17]. Thus, such a supported rehabilitation can extend beyond typical inpatient care and may be important and act as a bridge to patients and a stepping stone towards selfmanagement, autonomous behaviour and likely increase the psychosocial domains identified above following inpatient treatment [18]. Importantly, evidence has identified the importance of support interventions which can give problem solving skills, develop independence and educate patients on individuals' activities of daily living, although those with higher levels of disability may gain least from this [19]. Thus, given the above the aim of this study was to pilot an innovative and supported (see below for meaning) intervention for individuals with a stroke.

\section{Methods}

\subsection{Design and Conduct}

This pilot study was a single blind controlled trial conducted between January 2014 and March 2015. It was identified as a pilot as the feasibility of the intervention and the 11-week duration was established in previous research [18]. The conduct of the pilot intervention was informed by the medical research council framework (Craig [20] and includes; refining the choice of outcome measures taken forward, consideration of adherence within the intervention group as well as testing procedures for acceptability. Other outcomes include an ability to estimate recruitment rates and calculate sample sizes. The secondary aim was to compare the outcomes between an intervention and control group at baseline, 11 weeks, and 22 weeks and further consider a 52 week follow up for the intervention group.

${ }^{1}$ Defined as a sense of optimism, satisfaction, mastery of experiences and purpose in life, combined with a sense of control, belonging, as well as the perception of social support. 


\subsection{Participants}

\subsubsection{Eligibility Criteria}

Individuals were included if: (a) they had a clinical diagnosis of any type of stroke which was diagnosed at least 6 months ago, (b) were not undertaking inpatient rehabilitation, involved with other behaviour interventions or undertaking physical activity or exercise sessions more than once a week; however, they were included if they had previously been a member of the community rehabilitation unit run by the charity, (c) they were referred to the intervention by individuals or groups not associated with the NHS, (d) for the control group, that they were taking part in a stroke club in the west midlands which did not currently referral individuals to the Action After Stroke charity, (e) they did not suffer from cognitive or mental health impairments which prevented them from answering questionnaires.

The corresponding author made contact and invited individuals on to the trial. Individuals were assessed by a blind assessor (independent physiotherapist), or provided with a self-addressed envelope in order to complete the forms at home. All assessments were conducted in this way. Participants who completed the assessments were reimbursed with a $£ 20$ voucher. Ethical permission was gained through the University of Birmingham Ethics Committee (Ref: ERN_13-1091).

\subsubsection{Demographic Descriptors of the Sample}

We obtained self-reported demographics from participants which including gender, age, time since stroke and diagnosis.

\subsection{Outcome Measures}

We identified three outcome measures of interest (listed below) that were assessed at base line, 11 weeks, 22 weeks and 52 weeks for the intervention group. Each outcome measure was judged by authors on the paper able to influence the mental well-being of participants. We also undertook interviews around confidence and social identity (related to the charity i.e., an exercise group related identity) to consider the value of the intervention on participants.

\subsubsection{Self-Efficacy Questionnaire (SEQ) [21]}

This questionnaire is a 13-item questionnaire that identifies how confident individuals who suffered a stroke are with activities and tasks, which may have been affected following a stroke, as well as their perceived confidence in making further gains and improvements in these activities. A total maximum high score of 130 is possible; scoring is identified using a $0-10$ likert scale for each item. Two statements accompany the scale, a score of zero represents "not confident at all" and a score of 10 is identified as being "very confident". Psychometric testing of the scale has reported it to have a high construct validity [22].

\subsubsection{Short Falls Efficacy Scale (FES) [23]}

This FES is a 7-item questionnaire which identifies the fear of falling during specific tasks. Each item is assessed using a 4 point likert scale $(1=$ not at all concerned to $4=$ very concerned). A total of 28 is possible, representing the greatest fear of falling. The scale is thought to be a valid measure (Delbaere et al., 2010; Hauer et al., 2011). The scale has shown to have highly comparable test-re-test reliability, as well as comparable internal reliability with the 16-item version [24]. However, some research suggests that it has a floor effect, creating a greater skew of results with higher concerns about falling [25]. Although, recent guidelines identify the FES as an appropriate and adequate measure for clinical application [26].

\subsubsection{Single-Item Measure of Social Identification (SISI) [27]}

The 4-item social identification measure of was used to assess group membership or social identity within a group. The groups identified within the measure were the charity for the intervention group and "an exercise group" for the control group. The 4 items are assessed using a 7 point likert scale $(1=$ completely disagree to 7 $=$ completely agree. The total score is averaged.

\subsubsection{Semi-Structured Interviews}

Supplementary file A provides the interview schedules used to identify (a) if there were any changes in partici- 
pants confidence following the rehabilitation or (b) any changes to the participants social (exercise related) identity related to the rehabilitation group (participants undertaking the intervention) following the rehabilitation intervention. One interview within 4 weeks of the participants completing the 11-week intervention was undertaken. All interviews were conducted by authors (LD or SM), following training by the supervising author. Both were 21 years old and female, who had no prior relationship to the participants, but were able to disclose the purpose for the interviews. All interviews were undertaken in a private room within the University setting. The sample selected was a purposive sample from those that volunteered for the intervention. The average interview time was 27 minutes. All questions were asked to the participants.

\subsection{Procedure}

The study was undertaken at one community rehabilitation unit run by a charity (Action After Stroke) located in the west midlands of the UK. Following ethical approval the charity gave permission for its group to be used for assessment. Intervention participants were followed for a period of 1 year.

\subsubsection{Intervention}

Individuals selected for the intervention were recruited to the charity Action After Stroke. Action After Stroke located individuals by receiving patients from other local charities (predominantly from the stroke association) and through word of mouth. The intervention was based on the rehabilitation delivered by the charity. On attending the charity for the first time (introductory session and physical assessment) individuals were invited to participate in the study and provided with a participant information sheet. Individuals were given a week to consider if they would like to take part and provided with time to ask any questions or highlight any concerns they may have about participation. Individuals were provided with a pack to complete by the following week if they were interested in taking part. As part of the process for enrolling in the charity individuals were required to obtain a letter from their GP approving their participation.

A neurological physiotherapist, a level 4 register of exercise fitness professional attended the sessions. The physiotherapist designed the rehabilitation sessions for each individual; the fitness instructor was there for safety and instruction in applying the exercises. The intervention included 1 session of 45 minutes for 11 weeks. The setting was a private fitness studio or sports hall. The classes had substantial social support from physiotherapy students who volunteered their time. The role and function of the students is described in previous research [18]. Participants were stratified in to two groups depending on their ability at baseline, for those more able and not in a wheelchair there was use of a private fitness studio which enabled a tailored exercise program to include aerobic, strength, balance and flexibility. For those less able, access to a sports hall was provided participants to work on functional tasks such as sit-to-stands, recumbent cycling, bed mobility, assisted walking and functional tasks for developing fine motor skills. There was opportunity after each session for individuals to have a hot drink and a snack with students and staff.

\subsubsection{Control Group}

Participants were recruited from a local stroke club which met once a week for social activities and also organised day outings. The stroke club is a social club which provides social support and tea and coffee for members as well as outings and activities. Physical activity and exercise was not part of this provision and individuals attending the group appeared to have similar demographics to the individuals within the rehabilitation intervention. The group was chosen because it had not been used previously as a source of patients for the charity.

\subsubsection{Sample Size}

A minimum of 12 participants per group has been identified, when no prior knowledge of the population size exists [28]. This number is suggested to improve both the precision and feasibility of the study.

\subsubsection{Retention Rate}

Research suggests that attrition rates should be minimal to avoid biased results [29]. In order to enable clear results for the feasibility of a larger trial, a retention rate of $>80 \%$ had to be attained throughout the 22 weeks. Reasons for loss for follow-up were also provided. Within the intervention group retention achieved this. 


\subsubsection{Analysis}

The nature of this study meant that data were kept descriptive to portray the results [30]. Descriptive statistics are advised for use in pilot and feasibility studies as they allow a description of the data opposed to accepting or rejecting a given hypothesis [31]. Descriptive statistics and confidence intervals are provided for all outcome measures and a simple content analysis and descriptive summary of other data is provided. Base line characteristics are compared using a Mann-Whitney $U$ test. Analysis for the interview data was undertaking using a content analysis [32]; theoretical saturation of the major thematic units was achieved after 7 interviews but was continued until 8 interviews were complete. An audit trail of the process is available from the corresponding author.

\section{Results}

The consort flow diagram (Figure 1) provides details of the pathway taken by participants through the trial.

\subsection{Participant Recruitment-Intervention Group ${ }^{2}$}

Across the study period, 25 people recruited from local charities and organisations participated in weekly sessions

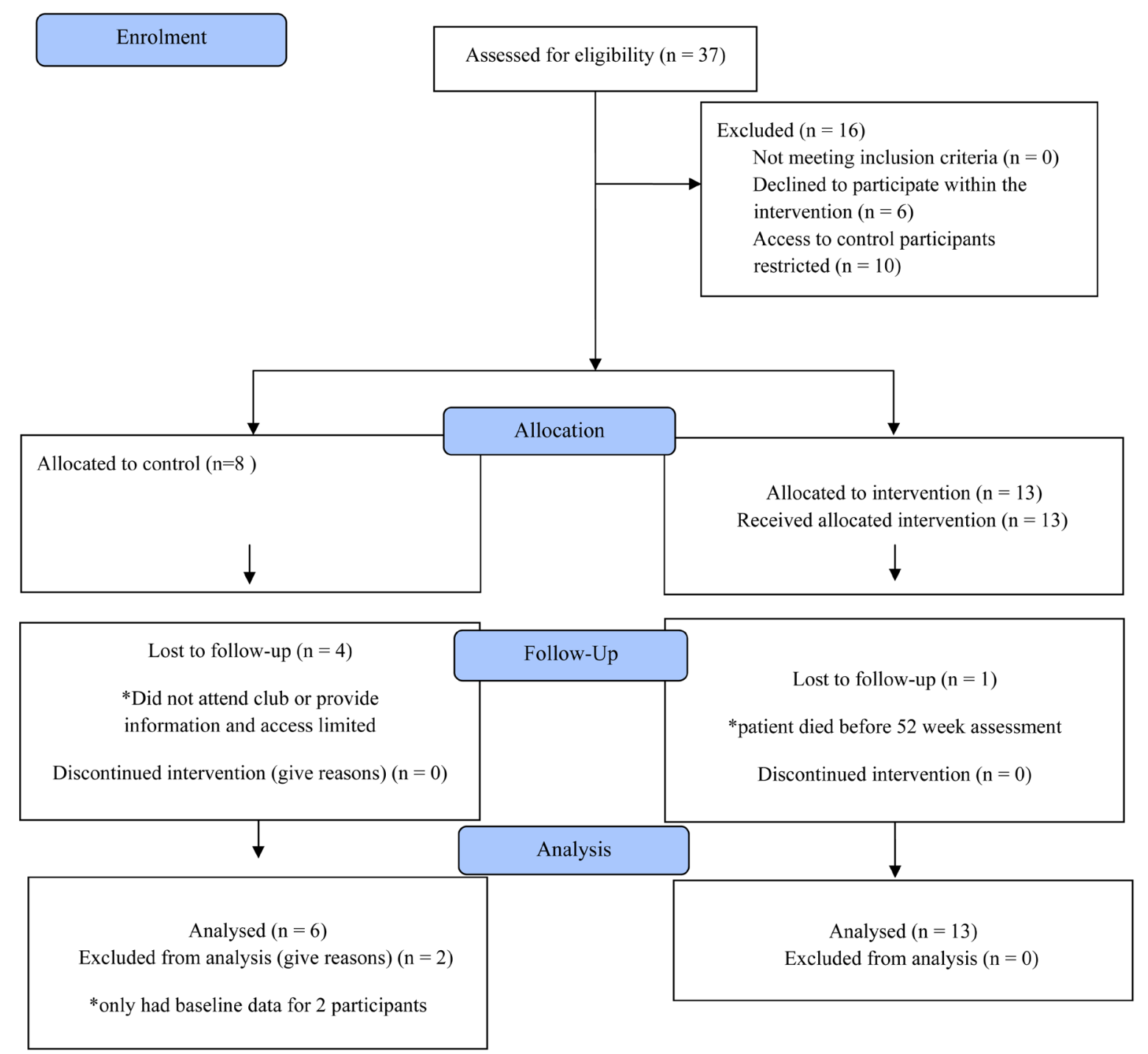

Figure 1. The CONSORT 2010 flow diagram representing study flow and recruitment.

${ }^{2}$ All comparisons made with a Mann-Whitney U test compare intervention to baseline characteristics. 
at the charity Action After Stroke. Of these, 19 participants were invited to participate, 13 individuals (6 male, 4 female; $\mathrm{U}=60.5, p=0.24$ ) met the inclusion criteria, consented and were included in this study. The average age was $70.7 \pm 13.5$ years $(\mathrm{U}=37.5, p=0.54)$ and the average time since stroke was $83.8 \pm 92.8$ months $(\mathrm{U}=$ $20, p=0.59)$. The average time at the charity was $10.8 \pm 5.9$ weeks. All participants had a clinical diagnosis of a cerebrovascular accident. Six participants declined to participate in the study. The primary reason for this was because they were not interested.

\subsection{Participant Recruitment-Control Group}

A total of 18 participants were available at the stroke club used for the control group. Seven individuals (2 male, 5 female, average age $67.9 \pm 9.4$ years) volunteered to represent the control group. The average time since stroke was $28.8 \pm 18.7$ months. All participants had a clinical diagnosis of having a cerebrovascular accident no further details were obtained. Limitations in access to a control group meant this fell short of the 12 participants hoped for; this is a key limitation of the current work. A table of all participant demographics is available from the supplementary files online.

\subsection{Participant Recruitment-Qualitative Study}

The eight participants completed one interview. The average (mean) age was 70 years (standard deviation (SD) 11.41); time since stroke, 6.25 years (SD 7.17); and time at charity, 14.3 (SD 3.4), and there were exactly 1:1 (female: male).

\subsection{Participant Retention-Intervention Group}

On average individuals attended $6.9 \pm 2.5$ sessions out of the possible 11 on offer. There was only two occasions when individuals provided a medical reason for not attending (either reporting a fall or medical illness). There were several occurrences when the bus service used to support individuals did not pick them up and so they missed the session. This is important because it would affect a large number of individuals $(n=8)$ who attended by this means. Other factors that influenced retention were the challenges experienced in having individuals complete the questionnaire after the session or having to prompt individuals $(n=3)$ to complete the questionnaires. Trial retention is show in Figure 1. One participant died which excluded him from the 52-week assessment.

\subsection{Participant Retention-Control Group}

Two individuals left the club after the first data collection and did not return. In the final data collection a further two individuals were ill. The main limitation to retention was ability to access group. For instance participants contact details were not provided. Figure 1 shows loss to follow up for the control and identifies 4 losses to follow up because of non-attendance at the club and inability to contact individuals.

\subsection{Outcome Measures}

Results from the SEQ (Jones et al., 2008) revealed little change in both groups across time, although both groups had large confidence intervals. The control group was noticeably lower scores across times. Interestingly the FES (Hauer et al., 2011) questionnaire identified a small positive change in self-efficacy in the intervention group after 11 weeks from the study, at the same time a small negative change occurred in the control group. However, within the intervention group results returned to baseline levels at 22 and 52 weeks assessments. Results from the SISI (Postmes et al., 2013) were the most positive showing a consistent improvement in the intervention group across each time period (weeks 22 and weeks 52 were very similar). In contrast the control group identified a reduction in identity levels at week 11 and a similar score to baseline at week 22. Table 1 provides details of the means, standard deviation and confidence intervals across time.

\subsection{Qualitative Data}

Three sub-themes relating to confidence and social identity were identified as benefits from the group, these domains included; psychological, quality of life and social. Within the psychological benefit there were 4 codes 
Table 1. Scores summarised by each outcome measure.

\begin{tabular}{|c|c|c|c|}
\hline Outcome & Week & $\begin{array}{c}\text { Intervention mean } \pm \text { SD CI } \\
\text { sample size }(n)\end{array}$ & $\begin{array}{c}\text { Control mean } \pm \text { SD CI } \\
\text { sample size (n) }\end{array}$ \\
\hline \multirow[t]{4}{*}{ Self-efficacy } & Baseline & $\begin{array}{c}65.1 \pm 37.9 \\
\text { CI: } 44.5-85.7 \\
n=13\end{array}$ & $\begin{array}{c}48.8 \pm 23.0 \\
\text { CI: } 30.4-67.2 \\
n=6\end{array}$ \\
\hline & 11 & $\begin{array}{c}65.1 \pm 32.0 \\
\text { CI: } 47.0-83.2 \\
n=13\end{array}$ & $\begin{array}{c}46.5 \pm 23.1 \\
\text { CI: } 28.0-65.0 \\
n=6\end{array}$ \\
\hline & 22 & $\begin{array}{c}60.9 \pm 38.3 \\
\text { CI: } 37.2-84.7 \\
n=13\end{array}$ & $\begin{array}{c}52.3 \pm 25.0 \\
\text { CI: } 28.3-77.2 \\
n=4\end{array}$ \\
\hline & 52 & $\begin{array}{c}65.7 \pm 39.9 \\
\text { CI: } 43.2-88.3 \\
n=12\end{array}$ & \\
\hline \multirow[t]{4}{*}{ Falls self - efficacy } & Baseline & $\begin{array}{c}15.7 \pm 7.11 \\
\text { CI: } 11.5-19.9 \\
n=11\end{array}$ & $\begin{array}{c}20.3 \pm 1.9 \\
\text { CI: } 18.8-21.8 \\
n=6\end{array}$ \\
\hline & 11 & $\begin{array}{c}17.3 \pm 6.3 \\
\text { CI: } 13.8-20.7 \\
n=13\end{array}$ & $\begin{array}{c}19.8 \pm 2.7 \\
\text { CI: } 17.7-22.0 \\
n=6\end{array}$ \\
\hline & 22 & $\begin{array}{l}16.0 \pm 7.0 \\
\text { CI: } 12.0-20.0 \\
n=12\end{array}$ & $\begin{array}{ll} & 20.5 \pm 1.9 \\
\text { CI: } \quad 18.6-22.4 & n=4\end{array}$ \\
\hline & 52 & $\begin{array}{c}15.9 \pm 7.6 \\
\text { CI: } 11.6-20.2 \\
n=12\end{array}$ & \\
\hline \multirow[t]{4}{*}{ Identity } & Baseline & $\begin{array}{c}5.5 \pm 0.72 \\
\text { CI: } 5.1-5.9 \\
n=13\end{array}$ & $\begin{array}{c}5.8 \pm 1.4 \\
\text { CI: } 4.7-6.9 \\
\quad n=6\end{array}$ \\
\hline & 11 & $\begin{array}{c}5.7 \pm 0.75 \\
\text { CI: } 5.3-6.1 \\
n=13\end{array}$ & $\begin{array}{c}5.1 \pm 2.0 \\
\text { CI: } 3.5-6.7 \\
n=6\end{array}$ \\
\hline & 22 & $\begin{array}{c}6.0 \pm 0.92 \\
\text { CI: } 5.5-6.5 \\
\quad n=12\end{array}$ & $\begin{array}{c}5.7 \pm 1.55 \\
\text { CI: } 4.2-7.2 \\
n=4\end{array}$ \\
\hline & 52 & $\begin{array}{c}5.9 \pm 1.05 \\
\text { CI: } 5.3-6.5 \\
n=10\end{array}$ & \\
\hline
\end{tabular}

or units identified by participants as benefits; (a) improvements in an individual's social confidence (4/8 participants). Importantly this is different from the SEQ as that refers to the confidence to complete certain tasks. (b) confidence gained from positive social comparisons (4/8 participants) with peers and the instructor. This aided the ability for individual to cope through being able to use strategies such as benefit finding or positive reappraisal of their own situation. (c) just attending the group allowed individuals were able to acknowledge their current ability (2/8 participants) and be more sure about what they could and couldn't do. (d) the final code identified the value and satisfaction from participants being able to help the student volunteers in their learning (3/8 participants) through direct and unique clinical experience. The second sub-theme related to benefits on an participants quality of life in that, individuals identified that sessions allowed them to engage in a meaningful activity (4/8 participants) by themselves (due to the ring and ride service), this impacted on their independence (a key aspect that influences mental well-being). The third sub-theme identified a social benefit from attending sessions which included four codes; (a) Participants identified receiving emotional and esteem support from 
individuals which aided their social confidence (4/8 participants). (b) participants reported a benefit in being able to relate to one another as well as experience a bond and unity of belonging to the group ( $3 / 8$ participants). (c) Participants identified the experience as occurring within a safe environment (2/8 participants) which was important for their confidence to initially attend the sessions. (d) Finally, individual talked about relatedness with others (3/8 participants). Table 2 provides a breakdown of themes with verbatim quotes.

Table 2. Confidence and social identity benefits identified by the intervention group participants.

\begin{tabular}{|c|c|c|c|}
\hline Subtheme & Code & Example Units & $\begin{array}{l}\text { Number of } \\
\text { participants } \\
\text { identifying code }\end{array}$ \\
\hline $\begin{array}{l}\text { Psychological } \\
\text { Benefit }\end{array}$ & Confidence & $\begin{array}{l}\text { "it hasn’t in as much as coming by ring and ride, coz now I can come on } \\
\text { that on my own, you know, which I wouldn’t have done, at first, at all.” (P4) } \\
\text { "Coming here gives you a lot more confidence in yourself.” (P2) } \\
\text { "Yes, sometimes before I start going here I used to fear to go out. You know, } \\
\text { but since I'm coming here I am more guts to go out.” (P3) }\end{array}$ & $\begin{array}{c}\text { P1, P2, P3, } \\
\text { P4, P7 } \\
\text { 4/8 participants }\end{array}$ \\
\hline & $\begin{array}{l}\text { Upward } \\
\text { social } \\
\text { comparison } \\
\text { and benefit } \\
\text { finding }\end{array}$ & $\begin{array}{c}\text { "I think [the leader] gives you lots of confidence because she’s } \\
\text { confident in herself”. (P2) } \\
\text { "I think meeting people who have got the same disabilities helps because } \\
\text { you can see how they progress, and you are too, progress the same” (P8) } \\
\text { Because I see them every week I can see how they progress, } \\
\text { and then I can see... (P7) }\end{array}$ & $\begin{array}{l}\text { P1, P2, P7, P8 } \\
\text { 4/8 participants }\end{array}$ \\
\hline & $\begin{array}{l}\text { Realisation or } \\
\text { acknowledgement } \\
\text { of ability }\end{array}$ & $\begin{array}{l}\text { "I think it’s helped me realise my limitations, because going round the } \\
\text { circuit that [physiotherapist leader's] done, I usually have to have a rest } \\
\text { in between. And its helped me realise that you do have to give into it } \\
\text { for a short while and then start again.” (P4) } \\
\text { Because I see them every week I can see how they progress, and then } \\
\text { I can see... I cant see myself obviously, my progress, but I've been told } \\
\text { I’m getting better at doing certain activities... with my hand, you know” (P7) }\end{array}$ & $\begin{array}{c}\text { P4, P7 } \\
\text { 2/8 participants }\end{array}$ \\
\hline & $\begin{array}{l}\text { Being able to } \\
\text { help others } \\
\text { (student volunteers) } \\
\text { by attending }\end{array}$ & $\begin{array}{l}\text { "Yes, that's it. From the students [volunteers], one exercise... All of it” (P6) } \\
\text { "oh definitely yes, because I'm helping them, obviously not helping } \\
\text { them but they're using me and I'm using them”. (P7) } \\
\text { "yes, and I think working with the students [volunteers] helps, } \\
\text { because a lot of physios, physio sessions iv been to, mainly are } \\
\text { for the elderly, and it's nice to have younger people around you” (P8) }\end{array}$ & $\begin{array}{c}\text { P6,P7,P8 } \\
\text { 3/8 participants }\end{array}$ \\
\hline $\begin{array}{l}\text { Quality of } \\
\text { life benefit }\end{array}$ & $\begin{array}{l}\text { Meaningful } \\
\text { activity which } \\
\text { is enjoyable }\end{array}$ & $\begin{array}{l}\text { "I like everything, I go round everything.” (P5) } \\
\text { "I look forward to it [coming to charity]” (P7) } \\
\text { "it’s given me...something to do on my own” (P4) }\end{array}$ & $\begin{array}{c}\text { P4,P5,P7,P7 } \\
\text { 4/8 participants }\end{array}$ \\
\hline \multirow{4}{*}{$\begin{array}{c}\text { Social } \\
\text { benefit }\end{array}$} & $\begin{array}{l}\text { Emotional and } \\
\text { esteem support } \\
\text { increasing social } \\
\text { confidence }\end{array}$ & $\begin{array}{l}\text { “It means being able to talk to people and is much easier now } \\
\text { with the group because we all talk.” (P1) } \\
\text { "I am louder when I am more comfortable with people.”(P3) } \\
\text { “... we chat on the bus... and look forward to seeing them” (P2) } \\
\text { I can’t see myself obviously, my progress, but I’ve been told I'm getting } \\
\text { better at doing certain activities... with my hand, you know” (P7) }\end{array}$ & $\begin{array}{c}\text { P1,P2,P3,P7 } \\
\text { 4/8 participants }\end{array}$ \\
\hline & $\begin{array}{l}\text { Sense of unity } \\
\text { and belonging }\end{array}$ & $\begin{array}{l}\text { "Now I feel I belong a lot more” (P1) } \\
\text { "it helps me seeing other disabled people” (P7) } \\
\text { "I come in and I like [patient at charity]" (P5) }\end{array}$ & $\begin{array}{c}\text { P1,P5,P7 } \\
\text { 3/8 participants }\end{array}$ \\
\hline & $\begin{array}{c}\text { Safe } \\
\text { experience }\end{array}$ & $\begin{array}{l}\text { "The only time I do go out on my own is here, with the ring and ride. } \\
\text { And that's the only time really that I'm on my own" (P4) } \\
\text { "As long as there's someone there to help me } \\
\text { it doesn't stop me going out." (P2) }\end{array}$ & $\begin{array}{c}\mathrm{P} 2, \mathrm{P} 4 \\
\text { 2/8 participants }\end{array}$ \\
\hline & $\begin{array}{c}\text { Relatedness and } \\
\text { shared experience }\end{array}$ & $\begin{array}{l}\text { "Because you're meeting other people that have got the same } \\
\text { problem as you so you don't feel like the odd one out.” P2 } \\
\text { "Because the people with the same complaint and has helped me } \\
\text { because they talking to me and listen to me and hold hands and talk } \\
\text { about the decision about the stroke and so I am more confident now”. P3 } \\
\text { "Mixing with people with the same sort of disability as myself” (P7) }\end{array}$ & $\begin{array}{c}\text { P2,P3,P7,P8 } \\
\text { 3/8 participants }\end{array}$ \\
\hline
\end{tabular}




\section{Discussion}

The current study demonstrated that social identity related to a supported rehabilitation group could be positively influenced over the 11-week intervention period and this could be maintained over a long-term duration of one year. Although further research is needed to confirm this, some improvement from the intervention was observed at 11 weeks from the falls self-efficacy scale in the intervention group but not control group. Interestingly, whilst no improvements were identified for participant's confidence (self-efficacy) in either group, improvements in an individual's social confidence were identified in the intervention group. The experience of individuals suggested that having a meaningful activity to attend provided them with confidence to do more, thus whilst they may not be confident in specific activities, they may be more confident in the ability to go out.

SEQ scores did not appear to respond to the current intervention, although a previous study by [21] identified significant change following a self-management program, importantly this research noted that changes in SEQ were not related mobility scores. The qualitative data in the current study identified that social confidence had improved and this likely impacted on individual's quality of life. The processes identified above are supported by a meta-analysis of the benefit of physiotherapy on the quality of life of patients who had suffered a stroke [3]. A fully powered study would require a measurement of quality of life within it.

Within the current study the improvement in falls self-efficacy may have contributed to the self-reported improvement in social activities and confidence. The reason for this may be that a decrease in the perceived risk of falling may aid the patients undertaking activities at home and within the community [33]. Further to this, significant and positive associations have been found between an individual's confidence and undertaking activities of daily living for community dwelling older adults [34]. It should be noted that an improvement in falls selfefficacy might not mean less falls [9]. The reason could be that those who fall less have low levels of falls self efficacy [35].

The main benefits of past community rehabilitation interventions have been noted on quality of life and social interaction [36] [37]. The current results support this and suggest that being involved in an exercise group likely helps the individuals initiate, re-access or maintain a positive athletic identity. Such a social identity likely helps them to overcome the challenges that face them as they learn to adapt to the sudden change to their previous sense of self [38]. Qualitative data was able to identify the social benefits of the group including emotional and esteem support as well as the social support mechanisms that may contribute to positive health behaviour change. Positive upward social comparisons (obtaining behaviour guidance from observing others), social control (explicit attempts to help others adopt or attain positive health practices) and a sense of belonging and self-esteem may be regarded as some of the mechanisms behind how a positive social identity is adopted [39].

\subsection{Implications}

The current results suggest that the outcomes focus on falls self-efficacy and social identity should be considered in a future fully powered trial. In addition, the results support the need for a quality of life measure, functional mobility measures and measures that can capture social support and/or a sense of belonging to a group.

Retention rates in this population can be poor due to cognitive difficulties and other co-morbidities that prevent follow-up from taking place [40], some evidence was identified in this study which supports this, the supported nature of the study and willingness of the group used may have enhanced this. A multi-centre trial is required in order to obtain enough individuals for a large scale study.

\subsection{Limitations}

Several limitations are noted: (a) the current pilot results should be interpreted with cautions when considering the requirement of sample size and response rate needed in a larger intervention [20]. (b) Individuals did not provide an accurate diagnosis that may impact the findings. (c) A quality of life outcome measure may have captured broader changes noted by the qualitative data. (d) Physical outcomes may have revealed important changes, which support and quantify the observation from the psychosocial results identified here. (e) There was a noticeable difference in groups between the average time since the stroke as well as the balance of male to female participants, both factors may have had an impact on the results.

\subsection{Conclusion}

The current study was able to highlight the importance of an individual's social identity, received social support 
and a sense of belonging obtained from a supported intervention. Further, adequately powered studies are required to confirm these findings and consider the use of other outcome measures.

\section{Acknowledgements}

We would like to thank the patients and physiotherapist (Ms Emily Hole) and fitness instructor (Mr Martin Barnes) for giving their time for the study.

\section{Funding}

This study was supported by a grant from Solihull Independent Hospitals.

\section{Conflict of Interest}

Three authors were associated with the charity that provided the intervention.

\section{References}

[1] National Institute for Health and Care Excellence (2013) Stroke Rehabiliation Long-Term Rehabiliation after Stroke. Nice Clinical Guideline 162, Ed. National Institute for Health and Care Excellence. National Institute for Health Care Excellence, London.

[2] The Stroke Association and The Chartered Soceity of Physiotherapy (2010) Moving on a Vision for Community Based Physiotherapy after Stroke in England. The Stroke Association, London.

[3] Pollock, A., Baer, G., Campbell, P., Choo, P., Forster, A., Morris, J., Pomeroy, V.M. and Langhorne, P. (2014) Physical Rehabilitation Approaches for the Recovery of Function and Mobility Following Stroke. Cochrane Database of Systematic Reviews, 4, CD001920. http://dx.doi.org/10.1002/14651858.cd001920.pub3

[4] Care Quality Commission (2011) Supporting Life after Stroke. Care Quality Commission, London.

[5] Aziz, N.A., Leonardi-Bee, J., Phillips, Gladman, J R., Legg, L. and Walker, M.F. (2008) Therapy-Based Rehabilitation Services for Patients Living at Home More than One Year after Stroke. Cochrane Database of Systematic Reviews, 16, CD005952. http://dx.doi.org/10.1002/14651858.cd005952.pub2

[6] Teasell, R., Mehta, S., Pereira, S., McIntyre, A., Janzen, S., Allen, L., Lobo, L. and Viana, R. (2012) Time to Rethink Long-Term Rehabilitation Management of Stroke Patients. Topics in Stroke Rehabilitation, 19, 457-462. http://dx.doi.org/10.1310/tsr1906-457

[7] Haworth, J., Young, C. and Thornton, E.W. (2009) The Effects of an "Exercise and Education” Programme on Exercise Self-Efficacy and Levels of Independent Activity in Adults with Acquired Neurological Pathologies: An Exploratory, Randomized Study. Clinical Rehabiliation, 23, 371-383. http://dx.doi.org/10.1177/0269215508101728

[8] Korpershoek, C., Van der Bijl, J. and Hafsteinsdotter, T. (2011) Self Efficacy and Its Influence on Recovery of Patients with a Stroke: A Systematic Review. Journal of Advanced Nursing, 67, 1876-1894. http://dx.doi.org/10.1111/j.1365-2648.2011.05659.x

[9] Batchelor, F.A., Hill, K.D., Mackintosh, S.F., Said, C.M. and Whitehead, C.H. (2012) Effects of a Multifactorial Falls Prevention Program for People with Stroke Returning Home after Rehabilitation: A Randomized Controlled Trial. Archives of Physical Medicine and Rehabilitation, 93, 1648-1655. http://dx.doi.org/10.1016/j.apmr.2012.03.031

[10] Haslam, C., Holme, A., Haslam, S.A., Iyer, A., Jetten, J. and Williams, W.H. (2008) Maintaining Group Membership: Social Identity Continuity Predicts Well-Being after Stroke. Neuropsychological Rehabilitation, 18, 671-691. http://dx.doi.org/10.1080/09602010701643449

[11] Hole, E., Stubbs, B., Roskell, C. and Soundy, A. (2014) The Patient's Experience of the Psychosocial Process That Influences Identity Following Stroke Rehabilitation: A Meta-Ethnography. The Scientific World Journal, 2014, Article ID: 349151.

[12] Soundy, A., Stubbs, B., Freeman, P., Coffee, P. and Roskell, C. (2014) Factors Influencing Patients’ Hope in Stroke and Spinal Cord Injury: A Narrative Review. International Journal of Therapy and Rehabilitation, 21, 210-218. http://dx.doi.org/10.12968/ijtr.2014.21.5.210

[13] Soundy, A., Liles, C., Stubbs, B. and Roskell, C. (2014) Identifying a Framework for Hope in Order to Establish the Importance of Generalised Hopes for Individuals Who Have Suffered a Stroke. Advances in Medicine, 2014, Article ID: 471874. http://dx.doi.org/10.1155/2014/471874

[14] Teo, K. and Slark, J. (2016) A Systematic Review of Studies Investigating the Care of Stroke Survivors in Long-Term Care Facilities. Disability and Rehabilitation, 38, 715-723. http://dx.doi.org/10.3109/09638288.2015.1059496 
[15] Morris, J.H., Oliver, T., Kroll, T., Joice, S. and Williams, B. (2015) From Physical and Functional to Continuity with Pre-Stroke Self and Participation in Valued Activities: A Qualitative Exploration of Stroke Survivors', Carers' and Physiotherapists' Perceptions of Physical Activity after Stroke. Disability and Rehabilitation, 37, 64-77. http://dx.doi.org/10.3109/09638288.2014.907828

[16] Jones, F. and Riazi, A. (2011) Self-Efficacy and Self-Management after Stroke: A Systematic Review. Disability and Rehabilitation, 33, 797-810. http://dx.doi.org/10.3109/09638288.2010.511415

[17] Cutrona, C.E. and Russell, D.W. (1990) Type of Social Support and Specific Stress: Toward a Theory of Optimal Matching. In: Sarason, B.R., Sarason, I.G. and Pierce, G.R., Eds., Social Support: An Interactional View, Wiley-Interscience, New York, 319-366.

[18] Soundy, A., Coffee, P., Anderson, C. and Stirling, S. (2013) The Feasibility of a Community-University Based Physiotherapy Programme for Stroke Patients for Student Learning and Patient Care. MedEdPublish, 2.

[19] Parke, H.L., Epiphaniou, E., Pearce, G., Taylor, S.J.C., Sheikh, A., Griffiths, C.J., Greenhalgh, T. and Pinnock, H. (2015) Self-Management Support Interventions for Stroke Survivors: A Systematic Meta-Review. PLoS ONE, 10, e0131448. http://dx.doi.org/10.1371/journal.pone.0131448

[20] Craig, P., Dieppe, P., Macintyre, S., Michie, S., Nazareth, I. and Petticrew, M. (2008) Developing and Evaluating Complex Interventions: New Guidance. Medical Research Council, London, 1-39.

[21] Jones, F., Partridge, C. and Reid, F. (2008) The Stroke Self-Efficacy Questionnaire: Measuring Individual Confidence in Functional Performance after Stroke. Journal of Clinical Nursing, 17, 244-252. http://dx.doi.org/10.1111/j.1365-2702.2008.02333.x

[22] Riazi, A., Aspden, T. and Jones, F. (2014) Stroke Self-Efficacy Questionnaire: A Rasch-Refinement of Confidence Post Stroke. Journal of Rehabilitation Medicine, 46, 406-412. http://dx.doi.org/10.2340/16501977-1789

[23] Hauer, K.A., Kempen, G.I.J.M., Schwenk, M., Yardley, L., Beyer, N., Todd, C., Oster, P. and Zijlstra, G.A.R. (2011) Validity and Sensitivity to Change of the Falls Efficacy Scales International to Assess Fear of Falling in Older Adults with and without Cognitive Impairment. Gerontology, 57, 462-472.

[24] Kempen, G.I.J.M., Yardley, L., van Haastregt, J.C., Zijstra, G.A., Beyer, N., Hauer, K. and Todd, C. (2008) The Short FES-I: A Shortened Version of the Falls Efficacy Scale-International to Assess Fear of Falling. Age and Ageing, 37, 45-50. http://dx.doi.org/10.1093/ageing/afm157

[25] Delbaere, K., Close, J.C., Mikolaizak, A.S., Sachdev, P.S., Brodaty, H. and Lord, S.R. (2010) The Falls Efficacy Scale International (FES-I). A Comprehensive Longitudinal Validation Study. Age and Ageing, 39, 210-216. http://dx.doi.org/10.1093/ageing/afp225

[26] Sullivan, J.E., Crowner, B.E., Kluding, P.M., Nichols, D., Rose, D.K., Yoshida, R. and Pinto Zipp, G. (2013) Outcome Measures for Individuals with Stroke: Process and Recommendations from the American Physical Therapy Association Neurology Section Task Force. Physical Therapy, 93, 1383-1386. http://dx.doi.org/10.2522/ptj.20120492

[27] Postmes, T., Haslam, S.A. and Jans, L. (2013) A Single-Item Measure of Social Identification: Reliability, Validity, and Utility. British Journal of Social Psychology, 52, 597-617. http://dx.doi.org/10.1111/bjso.12006

[28] Julious, S.A. (2005) Sample Size of 12 per Group Rule of Thumb for a Pilot Study. Pharmaceutical Statistics, 4, 287-291. http://dx.doi.org/10.1002/pst.185

[29] Hoffmann, T., Bennett, S. and Del Mar, C. (2010) Evidence-Based Practice across the Health Professions. Elsevier, Chatswood.

[30] Lancaster, G.A., Dodd, S. and Williamson, P.R. (2002) Design and Analysis of Pilot Studies: Recommendations for Good Practice. Journal of Evaluation in Clinical Practice, 10, 307-312. http://dx.doi.org/10.1111/j..2002.384.doc.X

[31] Tickle-Degnen, L. (2013) Nuts and Bolts of Conducting Feasibility Studies. American Journal of Occupational Therapy, 67, 171-176. http://dx.doi.org/10.5014/ajot.2013.006270

[32] Soundy, A., Smith, B., Butler, M., Minns Lowe, C., Dawes, H. and Windward, C. (2010) A Qualitative Study in Neurological Physiotherapy and Hope: Beyond Physical Improvement. Physiotherapy Theory and Practice, 26, 79-88. http://dx.doi.org/10.3109/09593980802634466

[33] Blennerhassett, J.M., Dite, W., Ramage, E.R. and Richmond, M.E. (2012) Changes in Balance and Walking from Stroke Rehabilitation to the Community: A Follow-Up Observational Study. Archives of Physical Medicine and Rehabilitation, 93, 1782-1787. http://dx.doi.org/10.1016/j.apmr.2012.04.005

[34] Tinetti, M.E., Mendes de Leon, C.F., Doucette, J.T. and Baker, D.I. (1994) Fear of Falling and Fall-Related Efficacy in Relationship to Functioning among Community-Living Elders. Journal of Gerontology, 49, 140-147. http://dx.doi.org/10.1093/geronj/49.3.M140

[35] Denkinger, M.D., Lukas, A., Nikolaus, T., Hauer, K., et al. (2015) Factors Associated with Fear of Falling and Associated Activity Restriction in Community-Dwelling Older Adults: A Systematic Review. American Journal of Geriatric Psychiatry, 23, 72-86. http://dx.doi.org/10.1016/j.jagp.2014.03.002 
[36] Harrington, R., Taylor, G., Hollinghurst, S., Reed, M., Kay, H. and Wood, V.A. (2010) A Community-Based Exercise and Education Scheme for Stroke Survivors: A Randomized Controlled Trial and Economic Evaluation. Clinical Rehabilitation, 24, 3-15. http://dx.doi.org/10.1177/0269215509347437

[37] Marsden, D., Quinn, R., Pond, N., Golledge, R., Neilson, C., White, J., McElduff, P. and Pollack, M. (2010) A Multidisciplinary Group Programme in Rural Settings for Community-Dwelling Chronic Stroke Survivors and Their Carers: A Pilot Randomized Controlled Trial. Clinical Rehabilitation, 24, 328-341. http://dx.doi.org/10.1177/0269215509344268

[38] Tasiemski, T. and Brewer, B.W. (2011) Athletic Identity, Sport Participation, and Psychological Adjustment in People with Spinal Cord Injury. Adapted Physical Activity Quarterly, 28, 233-250.

[39] Thoits, P.A. (2011) Mechanisms Linking Social Ties and Support to Physical and Mental Health. Journal of Health and Social Behavior, 52, 145-161. http://dx.doi.org/10.1177/0022146510395592

[40] Langhammer, B., Lindmark, B. and Stanghelle, J.K. (2014) Physiotherapy and Physical Functioning Post-Stroke: Exercise Habits and Functioning 4 Years Later? Long-Term Follow-Up after a 1-Year Long-Term Intervention Period: A Randomized Controlled Trial. Brain Injury, 28, 1396-1405. http://dx.doi.org/10.3109/02699052.2014.919534 